\title{
A Redução de Danos como estratégia de promoção de orientação e cuidados para usuários de drogas: uma revisão sobre experiências de alguns países \\ Jaqueline de Sousa Gomes ${ }^{1}$ \\ Nalayne Mendonça Pinto
}

Resumo: O objetivo deste artigo é apresentar uma revisão teórica sobre as experiências da Redução de Danos (RD) em alguns países e, em especial, a experiência brasileira, tendo em mente que a Redução de Danos não é hegemônica. Podemos notar uma disputa por terapêuticas no cenário de políticas públicas de saúde para usuários de drogas e entender principalmente que a Redução de Danos faz parte de um discurso de saber que opera sobre os corpos dos usuários de drogas. Nota-se que a exigência do abandono total do uso de drogas colabora com censuras direcionadas aos usuários, fazendo com que as instituições de saúde, em vez de serem agências produtoras de cidadania, são agências/territórios produtores de estigmas. A RD se apresenta como uma medida alternativa, que vai em contrapartida à política de guerra às drogas e pretende corrigir falhas nessa política, que não é democrática, apenas encarcera e mata extratos da sociedade que são estigmatizados.

Palavras-chave: Redução de danos. Usuários de drogas. Política de drogas. Saúde.

\section{Harm Reduction as a strategy to promote guidance and care for drug users: A review of experiences in some countries.}

\begin{abstract}
The objective of this article is to present a theoretical review on the experiences of Harm Reduction (DR) in some countries and mainly the Brazilian experience, bearing in mind that Harm Reduction is not hegemonic, as we can see a dispute for therapies in the scenario of public health policies for drug users and understand mainly that Harm Reduction is part of a discourse of knowledge that operates on the bodies of drug users. It is noted that the requirement of total abandonment of drug use collaborates with censorship directed at users, making these health institutions, instead of being agencies that produce citizenship, are agencies / territories that produce stigma. The DR presents itself as an alternative measure that goes against the policy of war on drugs, intends to correct flaws in this policy that is not democratic, only incarcerates and kills extracts from society that are stigmatized.
\end{abstract}

Key-word: Harm reduction. Drug users. Drug policy. Health.

Mestranda do Programa de Pós-Graduação em Ciências Sociais pela UFRRJ. Graduada em Ciências Sociais pela UFRRJ. E-mail: jaqueline-sgomes@hotmail.com

2 Doutora em Ciências Humanas (Sociologia) pela UFRJ (2006), Mestre em Sociologia e Antropologia pela UFRJ (2000). Professora associada do Departamento de Ciências Sociais e do Programa de Pós-Graduação em Ciências Sociais da UFRRJ. E-mail: nalaynempinto@gmail.com 


\section{Introdução}

O objetivo deste artigo $^{3}$ é apresentar uma revisão teórica sobre a experiência da Redução de Danos em alguns países e, em especial, a experiência brasileira, tendo em mente que a Redução de Danos não é hegemônica. Podemos notar uma luta por terapêuticas no cenário de políticas públicas de saúde para usuários de drogas e entender principalmente que a Redução de Danos faz parte de um discurso de saber que opera sobre os corpos dos usuários de drogas. Nele estão contidos acúmulos e reflexões em torno da temática da política de drogas brasileira e seus reflexos na política de segurança e saúde. O que nos levou ao tema da Redução de Danos (RD) foi o interesse nos estudos relacionados à política de drogas brasileira e, com aprofundamento nesse tema, notamos que os respectivos estudos sobre o tratamento dos usuários de drogas estão muito inclinados para a arena criminal e a arena médica, principalmente a psiquiátrica e a psicológica.

Em contrapartida, interessamo-nos notadamente pelos estudos com enfoque na questão de modelos de tratamento dos usuários de drogas, entendendo a Redução de Danos como um movimento democrático, de resistência, de luta por direitos e de cuidado com a nossa existência. Outra questão que nos levou a esse tema, como pesquisadoras da área das ciências sociais, foi a percepção da carência de estudos nesta área tão importante que é a saúde e a Redução de Danos. Urge, cada dia mais, um olhar diferenciado dos cientistas sociais sobre o campo das políticas públicas, na promoção da assistência e saúde para os usuários de drogas, baseadas em outros modelos de tratamentos. Para tanto, as diversas facetas devem ser exploradas e a relativização necessária deve se fazer presente para se entender os contextos - sejam eles culturais ou sociais - em que estão inseridos os usuários.

\section{Considerações sobre a evolução da política de Redução de Danos no cenário internacional}

De acordo com Pablo Ornelas Rosa - em seu trabalho Drogas e a governamentalidade neoliberal: uma genealogia da Redução de Danos (2014) - a Redução de Danos (RD) surge como um movimento de cunho político e internacional que visa à minimização das consequências danosas à saúde, decorrentes do uso inadequado de drogas. Essa política não leva em consideração a abstinência ou a internação compulsória como requisitos ou formas de se obter êxito no programa de RD. A gênese da Redução de Danos encontra solo fecundo nos países baixos europeus, como as primeiras investidas governamentais de alguns países que viam, nas ações pragmáticas da Redução de Danos, uma saída para conter o grande surto de contaminação pelo HIV e por hepatite virais, na década de 80, principalmente difundidas por UDI (Usuários de Drogas Injetáveis), profissionais do sexo, entre outros.

Gordon Allan Marlatt (1999), pesquisador comprometido com o tema da RD, teve seus estudos pautados em experiências concretas de Redução de Danos na Holanda, na Inglaterra, em outros países baixos, nos Estados Unidos, no Canadá e na Austrália. Embora seu trabalho não adentre muito na questão da política de drogas, nos dá uma grande compreensão da eficácia dessa política no campo da saúde. Como é uma experiência pragmática, é alçada pela efetividade.

Este artigo é um fragmento monográfico, resultado de um longo caminho de formação no Curso de Ciências Sociais - A Redução de Danos como estratégia de promoção de orientação e cuidados para usuários de drogas: uma Netnografia com a Rede Brasileira de Redução de Danos e Direitos Humanos - 2017, Monografia do Curso de Ciências Sociais, UFRRJ, sob a orientação da professora Dra. Nalayne Mendonça Pinto. 
Comecei a perceber que a redução de danos é muito mais do que apenas uma alternativa à abstinência no tratamento de dependência química e na prevenção do HIV/AIDS. A redução de danos trata do manejo seguro de uma ampla gama de comportamentos de alto risco e dos danos associados a eles. O importante não é se determinado comportamento é bom ou ruim, certo ou errado; na redução de danos, a ênfase é se o comportamento é seguro ou inseguro, favorável ou desfavorável. A redução de danos centra-se no que funciona (pragmatismo) e no que ajuda (empatia e solidariedade). (MARLATT, 1999, p.22).

Denis Roberto da Silva Petuco $(2016)^{4}$ nos mostra que o Reino Unido soube aproveitar bem a experiência no pós-guerra para o desenvolvimento de políticas públicas e estratégias inovadoras de cuidado em saúde. Com os impactos sofridos pela I Grande Guerra no campo da saúde, houve a problematização do grande aumento do uso de morfina e heroína, bastante difundidas na medicalização de soldados. Com esse cenário, houve o surgimento de medidas protetivas na minimização dos impactos causados pelo uso indevido de substâncias. Uma das experiências relatadas por Marlatt (1999) no campo da RD nos leva à Inglaterra - com esse cenário descrito acima. Iniciado com o Relatório Rolleston de 1926, o modelo de RD era conhecido, no Reino Unido, como "Minimização de Danos". Petuco (2016) vai assinalar esse marco como o primeiro nascimento da Redução de Danos. Segundo Rosa (2014), o relatório baseava-se em uma comissão interministerial, capitaneada pelo Sir. Humphrey Rolleston, Ministro da Saúde da Inglaterra naquela época. Assim o relatório dava o aval ao médico para livre prescrição legal de substância derivada do ópio para usuários de algumas drogas. De acordo com Marlatt (1999), o Reino Unido foi o primeiro no enfoque de "Medicalização", no qual dependentes de drogas podiam receber prescrições de drogas como heroína e cocaína para fins de manutenção.

Por mais que a prescrição de certas substâncias psicoativas àqueles indivíduos diagnosticados como dependentes químicos tenha sido desaprovada durante os anos subsequentes na Inglaterra, tal política voltou a ser praticada pelo departamento de saúde de Merseyside em 1990, atendendo às demandas na cidade de Liverpool (MARKS, 1991 apud MARLATT, 1999, p.35).

O modelo de RD de Merseyside disponibilizava uma gama de serviços a todos os dependentes que fossem cadastrados no Serviço de Dependência de Drogas, podendo incluir nesses serviços a troca de seringas; a prescrição de drogas como heroína e cocaína; a prescrição de receitas para usuários de drogas fumáveis, que são preparadas em forma de "baseados", ampolas ou aerossol, e até a disponibilização de serviços de moradias para os dependentes cadastrados (ROSA, 2014).

Marlatt (1999) assinala que cinco funções potenciais da abordagem da prescrição médica para dependentes são observadas por Strang (1990). Segundo ele, a primeira função se aplica à prescrição médica para alívio da abstinência. A exemplo disso, podemos observar a prescrição de Metadona ${ }^{\circledR}$ para dependentes de opiáceos. Em segunda função, observamos a prescrição como meio de atrair os dependentes, como se fosse uma estratégia de marketing, e já favorecendo a terceira função, a promoção da retenção desses usuários no programa, prevenindo o abandono ao tratamento. A quarta função se mostra bastante interessante para

PETUCO, Dênis Roberto da Silva. O pomo da discórdia? A constituição de um campo de lutas em torno das políticas públicas e das técnicas de cuidado em saúde dirigidas a pessoas que usam álcool e outras drogas no Brasil. Tese de Doutorado. UFJF, julho de 2016. 
análise: a prescrição médica como promotora de mudança na vida dos usuários dependentes, por meio de metas intermediárias no favorecimento de potencial mudança de hábito e, nas palavras de Marlatt (1999), "uma meta em curto prazo, que pode facilitar maiores avanços se o dependente iniciar um programa gradual de redução de danos do uso de drogas" (p.36).

Assim como Strang (1990), Marlatt (1999) chama a atenção para a importância da introdução de metas intermediárias na abordagem da RD no modelo Inglês. Essas metas intermediárias também são enfatizadas por Allan Parry (1989).

Se o funcionamento do tratamento for entendido como uma cascata de processos de mudança (seqüencial ou simultaneamente), com o estado final de cada processo atuando como uma hierarquia de metas, então o impacto benéfico da prescrição poderia ser avaliado de acordo com sua efetividade na realização de metas intermediárias. Algumas dessas metas intermediárias dentro da cascata ou de hierarquia poderiam ser vistas como particularmente importantes, tais como parar de compartilhar equipamentos de injeção, passar do uso de drogas injetáveis para uso exclusivo de drogas orais (STRANG, 1990 apud MARLATT, 1999, p. 36).

A quinta função envolve a prescrição de drogas, como heroína e Metadona ${ }^{\circledR}$, aos usuários que se mostrem incapazes ou, por livre vontade, de se manterem sem drogas. Dessa forma, podemos perceber certa horizontalização na organização dos serviços dos profissionais no programa de RD de Merseyside. As decisões são tomadas por membros de uma equipe interdisciplinar que, segundo Marlatt (1999), inclui médicos, assistentes sociais, enfermeiros e terapeutas. Assim, o programa de medicalização não é processado apenas pelo médico que prescreve a receita. Marlatt (1999) chama a atenção para a força policial, que desempenha um papel decisivo na abordagem de RD de Merseyside ${ }^{5}$. A força policial participa de comitês que aconselham infratores como uma forma de melhorar os programas de tratamento e prevenção de drogas. Sua política de advertência aconselha os usuários a não cometerem delitos futuramente, sujeitos a penas mais severas.

O caso holandês como modelo de RD também se mostra bastante interessante para análise, na medida em que nos fornece abundantes informações a respeito das medidas protetivas de Redução de Danos instituídas naquele país. De acordo com Petuco (2016), o segundo nascimento da Redução de Danos encontra-se na Holanda. Logo, para uma melhor compreensão do leitor, se faz necessário explicar o caso peculiar da política de RD nos moldes holandeses.

De acordo com Marlatt (1999), pode-se observar mudanças na política de drogas na Holanda, na década de 70, devido ao crescente problema das drogas emergente na década de 60. Nos países baixos, observa-se uma mudança na política de drogas já em 1972. Antes disso, na Holanda, usuários poderiam ter penas pesadas se fossem pegos portando drogas ilícitas. Em decorrência disso, a Lei Holandesa de Ópio de 1976 foi instituída e fazia a distinção entre drogas de maior risco, como heroína, anfetamina, cocaína e LSD, e as drogas de menor risco, como maconha e haxixe. Outra medida utilizada pela política de drogas foi a separação dos mercados de drogas pesadas das drogas consideradas leves, evitando que o usuário, ao procurar uma droga leve, se deparasse com outras drogas pesadas que estivessem a sua disposição.

Ver a respeito: Chappell, Reitsma, O’Connell \& Strang, 1993, apud Marlatt, 1999, p.36. 
Nos anos 80, surgiu uma nova filosofia de tratamento. Cada vez mais, o governo incentivava formas de auxílio, cujo principal objetivo não era eliminar o comportamento adictivo como tal, e sim, melhorar o bem-estar físico e social dos viciados e ajudá-los a atuarem socialmente. Nessa fase, a incapacidade (temporária) do viciado de abandonar o uso de drogas estava sendo aceita como fato. Esse tipo de assistência pode ser definido como Redução de Danos ou, em termos mais tradicionais, como prevenção secundária e terciária. Sua efetividade só pode ser assegurada por serviços de baixa exigência e auxílio acessível, os quais são conceitos-chave na política holandesa em relação às drogas. Isso toma a forma de: trabalho de campo nas ruas, em hospitais e em prisões; centros de livre circulação para prostitutas; fornecimento de Metadona ${ }^{\circledR}$ prescrita como droga substituta; apoio material; e oportunidades de reabilitação social (ENGLESMAN 1989, p.216, apud MARLATT, 1999, p.31).

Marlatt (1999), em uma de suas visitas ao Jellinekcentre ${ }^{6}$ de Amsterdã, pôde conhecer a perspectiva da Redução de Danos, aprendendo seus modelos básicos e pressupostos. O autor é enfático ao dizer que o movimento de RD holandês em busca de uma abordagem mais pragmática e humana foi estimulado devido à participação direta de usuários e dependentes químicos holandeses. Essa participação direta foi promovida pelo grupo Junkiebonds, que surge como vanguarda das primeiras investidas em programas de trocas de seringas (PTS), em Amsterdã, por volta de 1984. Os Junkies eram grupos locais surgidos em 1980, com representação nacional na federação holandesa de ligas de dependentes. Funcionava como um sindicato de dependentes químicos. Essa organização recebia toda semana seringas e agulhas limpas em trocas de seringas ou agulhas dos usuários, ministradas pelo serviço de saúde municipal.

Petuco (2016) vai nos mostrar que não foi o advento da AIDS que favoreceu o surgimento dos primeiros programas de troca de seringas (PTS). O autor assinala que o que fez com que surgisse esse programa foi a articulação de medos, medos da população de atenderem usuários de drogas injetáveis.

Diferentemente do que muitas pessoas acreditam, portanto, o primeiro programa de troca de seringas (PTS) não nasceu como uma estratégia para o enfrentamento da epidemia da AIDS, que na época ainda não era percebida como um problema entre pessoas que usavam drogas por via injetável. O que motivou o segundo nascimento da RD foi uma articulação de medos: o medo que tinham os funcionários de uma farmácia em atender pessoas que usam drogas injetáveis, e o medo das autoridades sanitárias holandesas diante de uma possível epidemia de hepatites virais (PETUCO, 2016, p.115).

O modelo de RD nos moldes holandeses, segundo Marlatt (1999), expandiu-se do modelo orientado de abstinência para abordagens múltiplas, abordagens essas que vão desde os programas de baixa exigência, como, por exemplo, a caminhoneta da Metadona ${ }^{\circledR}$, até programas de maior exigência, como comunidades terapêuticas. A caminhoneta da Metadona ${ }^{\circledR}$ não tem ponto fixo, não exige certo compromisso com a abstinência do dependente, nem que o dependente se comprometa com o tratamento. Apenas conseguem se tratar com esse medicamento os pacientes que estiverem inscritos no cadastro central da Metadona ${ }^{\circledR}$ e sob consulta médica.

Segundo Marlatt (1999), o nome é derivado de E. M. Jellinek, um importante estudioso norte-americano do alcoolismo. 
Durante minha visita ao Jellinekcentre em Amsterdã, observei a variedade de programas de tratamento disponíveis, desde projetos comunitários de baixa exigência (por exemplo, a "caminhoneta da metadona" sem ponto fixo) até programas de alta exigência, baseados em abstinência, para pacientes internados (por exemplo, comunidades terapêuticas e assistência domiciliar em longo prazo). Os programas de redução de danos incluem trabalho de campo com dependentes nas ruas, em hospitais e nas prisões; centros de livre circulação para profissionais do sexo; e amplos programas de trocas de seringas. Em contraste com programas de alta exigência, os programas de baixa exigência não exigem um comprometimento com a abstinência ou exame de drogas como pré-requisito para admissão. Tudo o que pedem do dependente é a disposição de aparecer e (espera-se) iniciar um movimento na direção de reduzir os danos associados ao uso de drogas (MARLATT, 1999, p. 32).

Rosa (2014) nos mostra que o programa de RD holandês, fundamentado no PTS que buscava a minimização da infecção por HIV, se mostrou extremamente eficaz, proporcionando a minimização da infecção por insumos. Em 1985, houve o estabelecimento de uma nova estrutura na revisão da política de drogas, a "normalização", que está voltada para as necessidades do usuário de drogas e almeja reduzir o mínimo os danos causados pelo consumo indevido de drogas. Segundo a política de normalização, o usuário pode ser observado como um holandês desempregado e não como uma ameaça ou risco para o país. $\mathrm{O}$ excerto a seguir pode explicar bem a normalização:

A posição holandesa delineada por Engelsman e seus compatriotas é resumida pelo termo "normalização". Ela se apresenta como uma posição política pragmática, que se coloca entre a guerra às drogas, por um lado, e a legalização, por outro. A normalização está, primordialmente, voltada às necessidades dos usuários de drogas e ao objetivo de reduzir ao mínimo todas as formas de danos que podem decorrer das respostas ao controle, distintas daquelas decorrentes do uso de drogas em si. Contudo, a normalização não significa desistir do cumprimento da lei. Trata-se de melhor ajustar o cumprimento da lei de modo a evitar a rotulação estigmatizadora dos usuários de drogas menos perigosas... Evidentemente, essa versão do pragmatismo (e trata-se de apenas uma versão entre muitas) seria como uma bandeira vermelha para um touro no que se refere a políticas de "tolerância zero" em qualquer país (DORN, 1989, p.995 apud MARLATT, 1999, p.32).

Marlatt (1999) salienta que qualquer tentativa de reprodução da política de drogas no molde holandês em outros países se mostra dificultosa devido a fatores culturais existentes. O autor mostra que a Holanda sofre críticas a respeito de sua política permissiva, frente a países com políticas mais repressivas de combate às drogas, como os Estados Unidos e alguns países da Europa que não fazem parte do bloco de políticas de RD. Dentre as críticas que repousam sobre os holandeses, podemos destacar o narcoturismo. Observando-se que o país recebe muitos turistas que frequentam coffeeshops, a preocupação das autoridades é de que essa prática fomentasse o contrabando de drogas para outros países. Em resposta a isso, o governo holandês instituiu, em sua agenda, uma política revisada de drogas, um relatório nomeado como "continuidade e mudança" (p.34), que limitava a quantidade de maconha que o usuário poderia adquirir, a fim de evitar sua revenda em outros países. Assim, a quantidade de maconha que os estabelecimentos poderiam vender reduziu de 30 gramas para 5 gramas. 
De acordo com Marlatt (1999), a experiência da RD também foi promovida por outros países da Europa, embora alguns países como a França e Suécia não tenham aceitado compor o bloco das políticas de $\mathrm{RD}$, devido à discordância com a política de drogas instituída em cada país.

A prática de RD instituída na Alemanha é vista por pesquisadores como um exemplo de Redução de Danos. Formado em 1990, o programa de Frankfurt oferece uma gama de tratamentos, que incluem serviços de baixa exigência, como caminhoneta móvel e o oferecimento de Metadona ${ }^{\circledR}$, programa de trocas de seringas para usuários, abrigos para dependentes, quatro centros de tratamento médico e três salas de assistência à saúde utilizadas para injeção de drogas pelo usuário. (MARLAT'T, 1999, p.38). Os efeitos positivos corroboram a importância do programa de RD naquele país.

A experiência suíça, iniciada em 1993, assinalada por Marlatt (1999), mostra que foi um programa voltado para atenção aos usuários de drogas pesadas, combinada com um estudo de três anos sobre política de drogas e distribuição de drogas pesadas para dependentes, capitaneada pela assistência médica e social (KARAEL, 1993, apud MARLAT'T, 1999, p.38). A Fixerstuebli, conhecida como sala do pico, oferece um lugar tranquilo e seguro para usuários poderem injetar-se drogas. Já a Plastžpitz, conhecida como parque da agulha, não obteve tanto sucesso, devido ao fato de ser um ambiente no qual os dependentes poderiam comprar e manusear drogas em ambiente público. Segundo Marlatt (1999), as autoridades suíças fecharam o projeto da Plastąpitz. em 1992, onde uma política de não intervenção era adotada desde que o parque tivera permissão para ser operado, em 1987.

Os governantes consideram uma abordagem alternativa: descentralizar os serviços e disponibilizar heroína e outras drogas injetáveis para dependentes pesados por meio de prescrições. Nesse novo programa, disponível em oito cidades suíças, os dependentes que se qualificassem para o programa tinham acesso à heroína, morfina e metadona injetável com acompanhamento médico, além de serviços que incluíam alojamento e auxílio na busca de emprego, tratamento para problemas somáticos e psiquiátricos (incluindo HIV) e aconselhamento para problemas de família e de estilo de vida. Embora a Suíça seja um país pequeno, cuja população é de apenas 6 milhões, estima-se que 30 a 40 mil pessoas sejam dependentes de drogas pesadas (MARLATT, 1999, p.38).

De acordo com Marlatt (1999), esse novo programa Suíço, em seu plano inicial, visava atingir cerca de 700 usuários. Só poderiam ser aceitos no programa usuários que fossem altamente dependentes. No verão de 1995, 340 dependentes de heroína suíços recebiam um suprimento legal de heroína por dia, de um dos programas de prescrições (MARLATT, 1999, p.39). Esses países citados acima, que compunham o bloco de RD nos moldes europeus, segundo Marlatt (1999), juntos, faziam parte da aliança para promoção de práticas de RD para usuários de drogas urbanas de alto risco. As evidências positivas explicitadas pelo autor também corroboram a importância da prática de Redução de Danos nesses países.

A política de RD aplicada na América tem como expoentes importantes o Canadá e o Brasil. A experiência brasileira de RD será abordada na próxima seção e não será explanada aqui.

Marlatt (1999) discorre que a primeira vez que a RD foi adotada como referencial de estratégia nacional de drogas no Canadá foi em 1987 O país sediou, em março de 1994, a V Conferência Internacional sobre Redução de Danos relacionados com drogas, na cidade de Toronto, que foi a primeira realizada na América do Norte. O modelo canadense reflete 
programas de UDI, programa de troca de seringas e manutenção com Metadona ${ }^{\circledR}$, incluindo também auxílio na prevenção de abusos com álcool, visando sempre à promoção e educação para a saúde.

A abordagem da redução de danos na educação focaliza informações neutras sobre as diferentes drogas, suas propriedades e efeitos, sobre leis e direitos legais, sobre como reduzir riscos e onde obter ajuda, se necessário. Ela ajuda os jovens a desenvolver uma grande variedade de habilidades na avaliação, no julgamento, na comunicação, na afirmação, na resolução de conflitos, na tomada de decisões e no uso seguro. A educação sobre a redução de danos baseia-se no humanitarismo, no pragmatismo e em uma abordagem científica de saúde pública. Os princípios da educação sobre drogas com redução de danos são os de que o uso de drogas é normal, que ele está associado a benefícios, bem como a riscos, que ele não pode ser completamente eliminado, mas que seus danos podem ser reduzidos; muitos jovens superam o uso de drogas; a educação deve ser isenta de julgamento; ela requer um diálogo aberto com jovens e respeito pelo direito das pessoas de tomarem suas próprias decisões; e enfatiza o apoio positivo dos parceiros e companheiros, e não separação (RILEY apud MARLATT, 1999, p.40).

Essa abordagem canadense explicitada por Marlatt (1999) reflete importante diálogo acerca de uma reformulação de educação sobre drogas no campo das políticas públicas de Redução de Danos. Essa abordagem mais educativa, segundo o autor, também é defendida na Austrália, que também introduziu a prática da Redução de Danos na sua agenda de política nacional de drogas. A Austrália sediou, em 1992, a III Conferência Internacional sobre Redução de Danos Relacionados a Drogas, com o objetivo de minimizar os danos e riscos causados pelo abuso de drogas. Segundo Marlatt (1999), o tabaco e o álcool são incluídos no eixo das drogas ilícitas, levando em consideração que são substâncias que causam a maioria dos riscos na Austrália.

\section{A política de Redução de Danos no Brasil: experiências e aproximações}

Historicamente a questão do uso abusivo e/ou da dependência de álcool e outras drogas tem sido abordada por uma perspectiva psiquiátrica e médica. Porém os aspectos psicológicos, econômicos e políticos também deveriam ser ressaltados para a resolução dos problemas com drogas. De acordo com Machado e Boarini (2013), no que se refere ao fenômeno das drogas, a transição do conceito de comportamento de risco para o conceito de vulnerabilidade permitiu o reconhecimento de que, além da perspectiva individual, a droga perpassa outras esferas no âmbito social, econômico e político, e que o comportamento individual é influenciado por essas instâncias.

Outro problema também importante a ser considerado é o fato de essa política muitas vezes estar associada a um discurso higienista de combate à criminalidade e às minorias estigmatizadas que são UDI ou usuários de álcool. Essa tendência reflete os discursos do campo da Segurança Pública, de uma política proibicionista, que corrobora com guerra às drogas, capitaneada pelos EUA. Essa política, de acordo com Machado e Boarini (2013), tinha o modelo de repressão e proibicionismo como pauta principal, objetivando, segundo as autoras, uma sociedade livre das drogas. (DELBON; DA ROS; FERREIRA, 2006). 
Forteski e Faria (2013) discorrem que, de acordo com Conte et al. (2004), a exigência de uma sociedade pautada na abstinência acaba determinando a marginalização do usuário, pois extirpa do sujeito a responsabilidade por suas escolhas. Podemos observar que a política de drogas no modelo repressivo, com sua política coercitiva, não prioriza o indivíduo e sua singularidade, além de mostrar uma nítida submissão dos campos da saúde ao poder jurídico, psiquiátrico e religioso. Forteski e Faria (2013) mostram, que, para Souza (2007), há uma necessidade constante dos defensores da RD de enfrentamento dos discursos de poder construído pela Psiquiatria, pelo Direito Penal e pelas instituições de confinamento, que se perpetuaram ao longo da história.

De acordo com Barroso e Silva (2011), a Reforma Psiquiátrica ${ }^{7}$ no Brasil completou 10 anos em 2011, com a Lei 10.216, chamada de Paulo Delgado, que altera a política de saúde mental. Segundo Gonçalves e Sena (2001), a respeito dos elementos para contextualizar a Reforma Psiquiátrica Brasileira, ela pode ser caracterizada como um movimento histórico de cunho político, social e econômico, que reflete ideologias de grupos dominantes. Os autores vão mais a fundo ao mostrarem que a principal vertente tem a desinstitucionalização e a desconstrução como paradigmas que sustentam a internação compulsiva em manicômios. Barroso e Silva (2011) discutem que, por meio da Lei Paulo Delgado, o modelo hospitalocêntrico foi substituído pelo modelo psiquiátrico comunitário de assistência, baseado em serviços de saúde mental descentralizados, multifuncionais e diversificados (ANDREOLI apud BARROSO; SILVA, 2011, p.67).

Santos e Oliveira (2013) apontam que, a partir de 1980, o Conselho Federal de Entorpecentes (CONFEN) fica responsável pela formulação de políticas púbicas para o enfrentamento das drogas. As autoras mostram que, embora a atuação do CONFEN tenha privilegiado as ações repressoras no enfrentamento das drogas, algumas iniciativas desse órgão promoveram a atenção ao usuário de álcool e outras drogas, dando ênfase ao apoio aos centros de tratamento referenciais, o fomento de comunidades terapêuticas.

De acordo com Rodrigues (2006), a década de 90, no Brasil, ficou marcada por dois movimentos de políticas públicas relacionadas com drogas que se opõem, ou seja, ao mesmo tempo em que houve um recrudescimento penal via justiça criminal, por outro lado, podemos notar um investimento na área da saúde no que diz respeito a políticas públicas de drogas. Segundo a autora, foi justamente a epidemia global da AIDS que levou à necessidade pragmática de implementação de medidas que pudessem reduzir os riscos de drogas, especialmente utilizadas por usuários de drogas injetáveis (UDI). De acordo com a autora, o programa de trocas de seringas (PTS) de Santos foi o pioneiro e era dirigido para UDI, a fim de evitar contaminação via seringas compartilhadas. Esse serviço também via a conscientização dos usuários como forma preventiva.

A partir da promulgação da Lei Paulo Delgado no 10.216 , de abril de 2001, dispondo sobre a proteção e o direito de pessoas portadoras de transtornos mentais e redirecionando o modelo assistencial em saúde mental, o Brasil adota uma legislação coerente com as diretrizes da Organização Mundial da Saúde. A Reforma Psiquiátrica é entendida como processo social complexo, envolvendo mudança em assistências de acordo com novos pressupostos éticos e técnicos. Disponível em: http://www.ccs.saude.gov.br/memoria\%20da \%20 loucura/mostra/reforma.html. 


\section{A experiência de Santos - SP}

A primeira vez em que se ouviu falar de Políticas de Redução de Danos no Brasil foi a experiência de Santos/São Paulo, em 1989, uma cidade portuária, onde havia uma grande circulação de pessoas e esse fato está intimamente ligado ao advento da AIDS no Brasil. De acordo com Petuco (2016), o marco do terceiro movimento da RD se encontra em solo nacional. Segundo o autor, Santos era a cidade brasileira com maior número de casos de AIDS, decorrentes do compartilhamento de seringas entre usuários de drogas injetáveis e da difusão também por profissionais do sexo. É importante pensar as primeiras investidas na Redução de Danos como política pública no âmbito da aprovação da Lei 8.080/90, que formalizou o papel do SUS, Sistema Único de Saúde, na política de enfrentamento da epidemia de AIDS. Esse processo contou com grande contribuição do então Secretário de Saúde e sanitarista, David Capistrano Filho, sob a coordenação de Fábio Mesquita. O grupo técnico envolvido nesse trabalho gerou as políticas do sistema público de Santos.

Uma série de experiências inéditas foram colocadas em prática: pela primeira vez, uma gestão pública fechava um hospital psiquiátrico e investia em iniciativas municipais de base territorial para o acompanhamento de pessoas em sofrimento mental; promoção de saúde e cidadania e prevenção das DST's e Aids na região portuária (voltada sobretudo às pessoas envolvidas com prostituição); criação do CRAids (Centro de Referência em AIDS), primeiro serviço do tipo no país; também em âmbito municipal, a abertura do Núcleo de Atenção a toxicodependentes... Estas e outras experimentações, que davam materialidade aos sonhos expressos pelos movimentos da Reforma Sanitária e da Reforma Psiquiátrica, estão registradas no livro "Contra a maré à beira mar: a experiência do SUS em Santos” (CAMPOS; HENRIQUES apud PETUCO, 2016, p.117).

Petuco (2016) argumenta que o medo e o preconceito sempre mataram mais que qualquer vírus. $\mathrm{O}$ autor quis mostrar como a iniciativa de Santos com os primeiros programas de RD foi desarticulada pelos setores mais conservadores da sociedade. Para Rodrigues (2006), essa primeira iniciativa de Redução de Danos em Santos não era sustentada por uma legislação e foi alvo de muitas ações civis e criminais, que lograram a descontinuidade das ações e o fim do programa. O material que fora utilizado pelos agentes de saúde foi retido e seus idealizadores foram submetidos a inquérito.

A intransigência articulada de setores conservadores bloqueou as trocas de seringas não apenas na cidade litorânea do estado de São Paulo, mas atrasou a implementação de estratégias voltadas à prevenção da Aids junto a pessoas que usavam drogas injetáveis em todo o país. Seria preciso esperar mais seis anos até que os soteropolitanos conseguissem realizar abertamente aquilo que os santistas foram obrigados a concretizar por meio de uma clandestinidade análoga à do próprio uso de substâncias qualificadas como ilícitas. (PETUCO, 2016, p.118).

Apenas em 1994, segundo Rodrigues (2006), o programa de RD foi oficialmente assumido como estratégia de saúde pública, sendo estimulada por experiências concretas de outros países. Machado e Boarini (2013) mostram que, em cooperação com o UNDC Programa das Nações Unidas para o Controle Internacional de Drogas, o Ministério da Saúde reconheceu a RD como estratégia de saúde pública no Brasil, em 1994. (BRASIL, 2003 apud MACHADO; BOARINI, 2013). 


\section{A experiência do CETAD, Salvador - BA}

O primeiro projeto de RD oficialmente assumido no Brasil sem clandestinidade foi criado em Salvador - BA. Petuco (2016) discorre que o êxito que a experiência de Salvador logrou foi devido a esse projeto ter nascido sob o aval do ambiente acadêmico e não como em Santos, que não tinha o aporte jurídico necessário, e por ter sido capitaneado por setores de organizações não-governamentais e autoridades locais. A criação do CETAD (Centro de Estudos e Terapia de Abuso de Drogas), uma iniciativa do Departamento de Anatomia Patológica e Medicina Legal da Universidade Federal da Bahia, por meio de recursos financiados pela Coordenação Nacional de DST/Aids e pelo Banco Mundial, consegue o fomento do primeiro PTS do Brasil, oficialmente legal em 1995 (PETUCO, 2016, p.119). Essas iniciativas, mais adiante, dão lugar a vários projetos espalhados pelo Brasil, com financiamento direto da Coordenação Nacional de DST/Aids.

\section{Terapia de substituição}

Uma experiência realizada pelo Programa de Orientação e Atendimento a Dependentes da Universidade Federal de São Paulo (PROAD/UNIFESP), entre 1996 e 1998, sob a orientação de Dartiu Xavier e Eliseu Labigalini, reflete o trabalho de terapia de substituição com dependentes de crack. Essa terapia é a substituição de uma droga por outra de mesmo efeito. Um exemplo disso é a administração de Metadona ${ }^{\circledR}$ e maconha para substituírem os efeitos da heroína e do crack. A pesquisa foi realizada com um grupo focal de 25 dependentes de crack, acompanhados por nove meses e sob o tratamento com maconha.

Os resultados demonstraram um salto positivo, com o abandono do crack por $68 \%$ dos pacientes (PETUCO, 2016, p.113). De acordo com Rosa (2012), embora alguns profissionais da saúde resistam à eficácia da RD no tratamento de dependentes de crack, por meio da aplicação de Cannabis, outros estudos corroboram a eficácia da RD no tratamento de dependentes de heroína e cocaína, por meio da ayuaska e ibogaína. McRae e Gorgulho (2003), discutindo sobre o tratamento de substituição do ponto de vista da REDUC - Rede Brasileira de Redução de Danos e Direitos Humanos, apontam que essa discussão ainda se mostra incipiente no Brasil e que, apesar de os estudos afirmarem resultados positivos, tem faltado ousadia técnica e política a outras instituições para darem continuidade a esse trabalho.

\section{Aborda e REDUC}

Petuco (2016) discorre que, em uma realização do II Congresso Brasileiro de Prevenção das DST/Aids, realizada em $1^{\circ}$ de dezembro de 1997, houve a criação da ABORDA - Associação Brasileira de Redutores de Danos e essa articulação vem desempenhando um papel técnico e político na RD no Brasil. Um ano depois da criação da ABORDA, em 1998, foi criada a REDUC - Rede Brasileira de Redução de Danos e Direitos Humanos, em um Encontro Nacional de Redução de Danos, em São Paulo. Petuco (2016) diferencia essas organizações da seguinte forma: a ABORDA reúne redutores e redutoras com experiência direta no campo da estratégia de Redução de Danos e a REDUC reúne um corpo mais acadêmico e técnico. (RIGONI, 2006, Apud PETUCO, 2016, p.119). 


\section{CONFEN e CONAD}

De acordo com Santos e Oliveira (2013), o órgão CONFEN, criado na década de 80, é substituído pelo CONAD - Conselho Nacional Antidrogas, vinculado ao gabinete da Segurança Institucional da Presidência da República. É um órgão normativo e deliberativo da Secretaria Nacional Antidrogas - SENAD, que institui o tema das drogas como pauta na Segurança Nacional. O CONAD tem como primeiro grande processo a formulação da Política Nacional Antidrogas - PNAD, instituída pelo Decreto 4.345/2002. Mesmo difundindo ideais proibicionistas, que objetivavam uma sociedade livre das drogas, a PNAD apoiava a criação e a implementação de estratégias de RD para o indivíduo, o grupo social ou a comunidade, com enfoque na prevenção das doenças infecciosas - ou seja, de medidas ainda restritas à prevenção de doenças - e na formação de redutores de danos. (BRASIL apud MACHADO; BOARINI, 2013).

Essas importantes mudanças no cenário político da época somadas s experiências adquiridas na implementação de programas de Redução de Danos na atenção à saúde de usuários de drogas injetáveis e a formulação da Política do Ministério da Saúde para Atenção Integral a Usuários de Álcool e Outras Drogas, contribuíram para o realinhamento discursivo na política do CONAD, a começar pelo nome, que mudou de 'Antidrogas' para "Políticas sobre Drogas". (SANTOS; OLIVEIRA, 2013, p.85).

Em 2002 é instituída a Lei Paulo Delgado no 10.216/2001. Por meio dela, o tratamento do dependente passa a ser realizado de forma multiprofissional e com assistência familiar quando possível. Segundo Santos e Oliveira (2013), houve aí a primeira menção, na legislação brasileira, sobre RD e, incumbido dessa regulação, ficou o Ministério da Saúde.

O CONAD, em 2005, aprovou a Política Nacional sobre Drogas. Segundo Santos e Oliveira (2013), essa política admite a importância da inclusão da questão do uso abusivo de drogas como problema de saúde pública, admitindo a necessidade de tratamento, recuperação e reinserção social do usuário de álcool e outras drogas.

A Política Nacional sobre Drogas tem como principais diretrizes: atingir o ideal de construção de uma sociedade protegida do uso de drogas; reconhecer o direito de toda pessoa receber tratamento para drogadição; reconhecer as diferenças entre o usuário, a pessoa em uso indevido, o dependente e o traficante; priorizar ações de prevenção; incentivar ações integradas aos setores de educação, saúde e segurança pública; promover ações de redução de danos; garantir ações para reduzir a oferta de drogas no país, entre outras orientações. (SANTO; OLIVEIRA, 2013, p.85).

\section{Redirecionamento da política de atenção psicossocial: CAPS e CAPSad}

Em 2003, o Ministério da Saúde publicou um documento com a Política do Ministério da Saúde para Atenção Integral a Usuários de Álcool e Outras Drogas. Repousando-se nos princípios do SUS e na Reforma Psiquiátrica, se orienta através do fortalecimento de um trabalho de rede, de atenção integral, com fácil acesso aos serviços, participação do usuário no tratamento e oferta de serviços de atenção diária como alternativa ao hospital psiquiátrico, o CAPS - Centro de Apoio Psicossocial e o CAPSad - Centro de Apoio Psicossocial álcool e drogas. (SANTOS; OLIVEIRA, 2013, p.86). 
Esse CAPS e sua modalidade para atendimento exclusivo para usuário de álcool e drogas - CAPSad - é a expressão prática da Reforma Psiquiátrica, pois trata-se de uma modalidade de atenção à saúde centrada na comunidade, caracterizada por atendimento ambulatorial, realizado por uma equipe multiprofissional especializada, articulando ações de redução de danos, prevenção, recuperação, tratamento e reinserção social dos usuários de drogas de abuso [SIC]. (SANTOS; OLIVEIRA, 2013, p.86).

De acordo com Delbon, Da Ros e Ferreira (2006), as redes assistenciais do CAPS são serviços comunitários que objetivam o cuidado no trato de pessoas com transtornos mentais. Sua atenção repousa em ações conjuntas com os familiares e com o intuito da reinserção social dos usuários. O CAPSad repousa em ações centrais na atenção aos usuários de álcool e outras drogas e há também um trabalho conjunto com familiares dse usuário de álcool e drogas.

O uso destas medidas permite que sejam elaborados projetos terapêuticos mais flexíveis e de menor exigência, consequentemente adequados às necessidades de cada usuário dos serviços. Os CAPSad atuam de forma articulada a outros dispositivos assistenciais em saúde mental (ambulatórios, leitos em hospital-geral, hospitais - dia) e da rede básica de saúde, bem como ao Programa de Saúde da Família e ao Programa de Agentes Comunitários de Saúde. (DELBON; DA ROS; FERREIRA, 2006, p.41).

No município de São Paulo, os levantamentos epidemiológicos apontam que 20\% da população apresentam transtornos mentais comuns, como quadros depressivos e ansiosos e por abuso ou dependência de álcool (DELBON; DA ROS; FERREIRA, 2006. Em decorrência desse quadro, foi necessária a parceria entre as áreas da Saúde Mental Álcool e Drogas e DST/ AIDS, pelo Programa de Redução de Danos, o PRD - Sampa.

Nesses serviços de tratamento busca-se oferecer um acolhimento diferenciado, recursos para uso mais seguro, disponibilização de kits de redução de danos contendo: seringas, agulhas, swabs, preservativos, água destilada, copo plástico e material informativo. Constitui-se uma política de atendimento que trabalha com a realidade do fenômeno droga e de seus consumidores, suas necessidades e principalmente suas possibilidades, visando incluir e amparar socialmente o usuário de drogas. (DELBON; DA ROS; FERREIRA, 2006, p.42).

É muito interessante e importante, dentro da proposta da Redução de Danos, a figura emergente do redutor de danos, que é o agente responsável pela eficácia dessa política, tendo em vista a facilidade de inserção direta no campo da execução da política ou nos locais de fácil acesso aos usuários em cenas de uso. $\mathrm{O}$ quadro de redutores inclui também representantes ex-usuários, ou usuários na ativa. Assim, o conhecimento da realidade dos usuários pode permitir a obtenção de bons resultados pela relação direta com UDIs. De acordo com Delbon, Da Ros e Ferreira (2006), a Secretaria Municipal de Saúde elabora o projeto de "Treinamento de Capacitação de Profissionais dos Centros de Atenção Psicossocial Álcool e Drogas”, objetivando a sensibilização de profissionais no acolhimento de usuários e disponibilização de kits de Redução de Danos. Esses autores mostram que, em uma pesquisa realizada sobre a avaliação de distribuição de kits de redução de danos no município de São Paulo, com o programa PRD Sampa, no período de 2003 a 2004, observou-se a eficácia na adesão desse programa. Tais estudos corroboram, portanto, a efetividade dessa política. O PRD Sampa compreende quase 10.000 UDIs, acessados em 2003. Essa estratégia trouxe conhecimento às autoridades de saúde, sobre essa população que, até então, se mostrava invisível. 


\section{PEAD}

Santos e Oliveira (2013) discorrem que, diante da necessidade de intensificar e ampliar as ações de promoção, prevenção, tratamento e redução de riscos, o Ministério da Saúde, em 2009, instituiu o Plano Emergencial de Ampliação do Acesso ao Tratamento e Prevenção em Álcool e Outras Drogas - PEAD no SUS.

Essa nova diretriz política objetivou aumentar o leque de ação das diretrizes anteriores. As finalidades são: ampliar o acesso ao tratamento e à prevenção em álcool e outras drogas no SUS; diversificar as ações orientadas para a prevenção, promoção da saúde, tratamento e redução de riscos e danos associados ao consumo prejudicial de substâncias psicoativas; e construir respostas intersetoriais efetivas, sensíveis ao ambiente cultural, aos direitos humanos e às peculiaridades da clínica do álcool e outras drogas, e capazes de enfrentar, de modo sustentável, a situação de vulnerabilidade e exclusão social dos usuários. (SANTOS; OLIVEIRA, 2013, p.87).

O PEAD objetivou a ampliação do acesso dos dependentes ao tratamento preventivo, no SUS. Consistiu em um plano com metas num intervalo de 2009 a 2010, com a participação de 100 municípios que se enquadravam na categoria de fragilidade assistencial ao dependente químico e devido ao grande problema das drogas enfrentado por esses municípios. (MACHADO; BOARINI, 2013.

\section{A onda do crack e novas drogas no cenário moderno}

Para Santos e Oliveira (2013), o foco de ação das políticas dos Estados Modernos se concentra além de drogas tipicamente conhecidas como tabaco, álcool, ópio e cocaína, mas também no surgimento de novos tipos de drogas, como é o caso de drogas sintetizadas, produzidas em âmbitos laboratoriais, como ecstazy (metanfetaminas), solventes, inalantes e LSD, e o "oxi”, uma derivação do crack que tem, em sua composição, constituintes mais tóxicos.

O crack tem seu surgimento nos anos 80. De acordo com Santos e Oliveira (2013), constitui um composto potente, de efeito curto e com alto grau de dependência. Originalmente produzido artesanalmente, acabou se transformando em uma mercadoria mais barata e acessível (DOMANICO, 2006 apud PETUCO, 2016, p.120).

A configuração atual do cenário das drogas no País demanda a avaliação e a construção de estratégias de redução de danos que contemplem a especificidade de cada droga, pois o contexto em que surgiu a estratégia de $\mathrm{RD}$ no Brasil por meio dos programas de troca de seringas não é mais hegemônico, uma vez que as drogas injetáveis deram espaço a uma gama de outras drogas usadas de diferentes formas, que exigem, por isso mesmo, novas estratégias e adequação da redução de danos a essas outras realidades sociais. (MACHADO; BOARINI, 2013, p.590).

O Plano Integrado de Enfrentamento ao Crack foi instituído em 2010, por meio do Ministério da Saúde e órgãos governamentais, visando à prevenção do uso, ao tratamento e à reinserção social dos dependentes. Santos e Oliveira (2013) discorrem que os objetivos do plano são articulação e ampliação das ações de prevenção e reinserção social, dando vistas à participação familiar e comunitária nas políticas, ao fortalecimento de redes de atenção à saúde e assistência social para os dependentes. De acordo com Rosa (2012), as estratégias de $\mathrm{RD}$ para usuários de crack envolvem distribuição de preservativos, cuidados com a prática 
de sexo mais seguro, informações sobre riscos de contaminação pelo compartilhamento de seringas, oferecimento de cachimbos de melhor qualidade, evitando a contaminação por bactérias. Forteski e Faria (2013) mostram que, para Alves (2009), a exigência do abandono sistemático do uso de drogas colabora com censuras direcionadas aos usuários, fazendo com que as instituições de saúde sejam territórios produtores de estigmas.

As propostas de Redução de Danos se mostram pragmáticas e de baixa exigência. Compreendem uma abordagem mais humanitária, que não pauta a abstinência como ponto de partida, tampouco incentiva o uso desordenado de drogas, sejam elas lícitas ou ilícitas. Essa proposta se mostra eficiente na medida em que podemos observar os saltos positivos desde a afirmação dessa estratégia como política pública, mesmo que seus recursos ainda sejam incipientes. É necessária uma interdisciplinaridade dos campos de saberes, uma união comum, tendo em vista as intermitências e dificuldades de sistematização dessa política. A política de Redução de Danos deve ser aplicada a um território produtor de cidadania e não de estigma. Destarte, de acordo com Passos e Souza (2011), a análise de como ocorre a inclusão dos usuários de drogas em arranjos coletivos de gestão é uma importante direção clínica e política do movimento de Redução de Danos, pois define uma nova proposta de atenção salutar. Os autores mostram que, a partir desses espaços coletivos de cuidado, os usuários puderam tecer uma rede nacional de cooperação e de produção de uma luta que é de todos.

Estas estratégias de controle sobre drogas foram se constituindo ao longo da história brasileira de acordo com a complexidade dos desafios enfrentados pelo Estado. No entanto, a lógica territorial baseada na articulação de redes, proposta pela redução de danos, passou a ser desenvolvida por meio do reconhecimento da importância do trabalho de campo vinculado ao meio cultural e à comunidade em que os usuários de drogas estão inseridos. (ROSA, 2012, p.226).

Podemos compreender que a Redução de Danos pode ser uma estratégia de ação educativa em drogas, priorizando um diálogo aberto com os jovens. A RD se mostra como ação educativa, pautada na realidade e na emancipação dos sujeitos, uma ferramenta facilitadora de posturas preventivas, exigindo a articulação prática de conduta individual e coletiva, não submetendo seus usuários a modelos rígidos de comportamento, respeitando as diferenças e buscando uma promoção de saúde para todos. (FEFFERMANN; FIGUEIREDO, 2006).

\section{Considerações Finais}

O cenário atual é marcado por uma atmosfera nacional de lutas, com movimentos importantes, como os movimentos sociais em prol da legalização, as marchas nacionais da maconha e a luta das mães pelo salvo conduto, para que seus filhos possam ser medicados pelo Cannabidiol. Esses atores emergem como atores centrais pela luta por políticas menos repressivas e políticas que objetivem ampla participação da sociedade civil. Atualmente podemos perceber uma situação desfavorável à política de drogas nacional, dada a mudança de governança, com profundos desmanches na área de políticas públicas voltadas para usuários de drogas. Tais ações inviabilizam tanto as próprias políticas que sejam promotoras de igualdades e direitos humanos, como o cenário de pesquisas sociais voltadas para esse âmbito.

Como já sabido, a Redução de Danos foi retirada da agenda pública da política atual, cenário que corrobora grandes fomentos às comunidades terapêuticas de cunho religioso. Podemos perceber que há uma atmosfera de disputas por terapêuticas, com saberes diferenciados 
que lutam por visibilidade. Por isso, há uma necessidade constante dos defensores da Redução de Danos (RD) de enfrentamento dos discursos de poder construídos pela Psiquiatria, pelo Direito Penal e pelas instituições de confinamento que se perpetuaram ao longo da história, que, para Goffman (1961), são caracterizadas como "instituições totais". Por "instituições totais", o autor entende locais onde vários indivíduos se encontram na mesma situação, separados da sociedade, com uma vida fechada e administrada por considerável tempo, levando o indivíduo a uma "mortificação do eu". O mais importante é deixar claro que esse cenário obscuro não anula a pauta dos defensores da Redução de Danos, pois existem outras formas de atuação, como grupos de pressão, militância, organizações não governamentais, que tecem uma rede comum em prol das defesas dos usuários.

Forteski e Faria (2013), acionando a concepção de Alves (2009), mostram que a exigência do abandono total do uso de drogas colabora com censuras direcionadas aos usuários, fazendo com que essas instituições de saúde, em vez de serem agências produtoras de cidadania, sejam agências/territórios produtores de estigmas. É necessária, portanto, uma ação conjunta entre setores que trabalham e norteiam a Redução de Danos.

Neste trabalho, fez-se premente um questionamento sobre o papel de ação protetiva que, ao mesmo tempo em que é produzida pelos sujeitos que são usuários, os conduz a agirem como ferramentas de autoproteção, em reação à política criminalizadora promovida pelo Estado. Para Passos e Souza (2011), os espaços de cuidado coletivo permitem que os usuários teçam uma rede coletiva de cooperação e de produção em prol de uma luta comum solidária. Então, os sujeitos se fazem protagonistas de sua própria ação. Por isso, o histórico da Redução de Danos pode ser considerado como um histórico de lutas em prol da promoção de igualdade e direitos para os usuários de drogas.

Para finalizarmos este trabalho, trazemos as palavras de um pesquisador da Redução de Danos que participou de um Seminário de Redução de Sanos na Educação Básica, que aconteceu em 2016, na FioCruz: Marcelo Sodeli. Segundo ele, a Redução de Danos é uma luta diária, que prima pelo cuidado da nossa existência.

\section{Referências}

ALVES, V. S. Modelos de atenção à saúde de usuários de álcool e outras drogas: discursos políticos, saberes e práticas. Caderno de Saúde Pública, São Paulo, v. 25, n. 11, p. 2309-2319, 2009.

BARROSO, S, M; SILVA, M.A. A reforma psiquiátrica brasileira: o caminho da desinstitucionalização pelo olhar da historiografia. Revista da SPAGESP - Sociedade de Psicoterapias Analíticas Grupais do Estado de São Paulo, v. 12, n. 1, p. 66-78, jan - jun., 2011.

BRASIL. Ministério da Saúde. Secretaria Executiva. Coordenação Nacional de DST/Aids. A Política do Ministério da Saúde para atenção integral a usuários de álcool e outras droga.- Brasília: Ministério da Saúde, 2003.

BRASIL. Ministério da Saúde. Lei n. 10.216, de 6 de abril de 2001. Dispõe sobre a proteção e os direitos das pessoas portadoras de transtornos mentais e redireciona o modelo assistencial em saúde mental. Diário Oficial da União, seção 1.

CONTE, M. et al. Redução de danos e saúde mental na perspectiva da atenção básica. Boletim da Saúde, Porto Alegre, v. 18, n. 1, jan./jun. 2004. 
DELBON, F.; DA ROS, V.; FERREIRA, E. M. Avaliação da disponibilização de kits de Redução de Danos. Revista Saúde e Sociedade, São Paulo, v. 15, n. 1, p. 37-48, 2006.

FEFFERMANN, M; FIGUEIREDO, R. Redução de Danos como estratégia de prevenção de drogas entre jovens. Boletim do Instituto de Saúde, São Paulo, Instituto de Saúde - SES, 2006.

FORTESKI, Rosina; FARIA, Jeovane Gomes de. Estratégia da Redução de Danos: um exercício de equidade e cidadania na atenção a usuários de Drogas. Rev. saúde pública. Santa Catarina, v.6, n,2.,p. 78-91, 2013.

GOFFMAN, E. Manicômios, prisões, conventos. São Paulo, Perspectiva, 2008. [1961].

GOMES, J. S. A Redução de Danos como estratégia de promoção de orientação e cuidados para usuários de drogas: Uma Netnografia com a Rede Brasileira de Redução de Danos e Direitos Humanos. 2017, Monografia do curso de Ciências Sociais, UFRRJ.

GONÇALVES, A. M; SENA, R. R. A Reforma Psiquiátrica no Brasil: Contextualização e Reflexos sobre o cuidado com o doente mental na família. Rev. Latino - Americana de Enfermagem, 2001, março; 9 (2): 48:55.

BRASIL. Ministério da Saúde. Lei n. 10.216, de 6 de abril de 2001. Dispõe sobre a proteção e os direitos das pessoas portadoras de transtornos mentais e redireciona o modelo assistencial em saúde mental. Diário Oficial da União, seção 1.

MACHADO, Letícia Vier; BOARINI, Maria Lúcia. Políticas sobre drogas no Brasil: a estratégia de Redução de Danos. Psicologia: Ciência E Profissão [online], v. 33, n. 3, p. 580-595, 2013.

MAcRae, Edward; GORGULHO, Mônica. Redução de Danos e Tratamento de Substituição, Posicionamento da Reduc (Rede Brasileira de Redução de Danos). Jornal Brasileiro de Psiquiatria, vol. 52, set-out 2003, PP 371-374.

MARLATT, G. Allan. Redução de Danos no mundo: uma breve história. In. MARLATT, G. Allan (Org.). Redução de Danos: estratégias práticas para lidar com comportamentos de alto risco. Porto Alegre: Ed. Artmed, 1999.

PARRY, A. (1989). Harm reduction [Interview], Drug Policy Letter 1(4). 13.

PASSOS, E. H.; SOUZA, T. P. Redução de danos e saúde pública: construções alternativas à política global de “guerra às drogas". Psicologia \& Sociedade, v.23, n. 1, p.154-162, 2011.

PETUCO, Dênis Roberto da Silva. O pomo da discórdia? A Constituição de um campo de lutas em torno das políticas públicas e das técnicas de cuidado em saúde dirigidas a pessoas que usam álcool e outras drogas no Brasil. Doutorado, UFJF, julho de 2016.

RODRIGUES, L. B. F. Controle penal sobre as drogas ilícitas: o impacto do proibicionismo no sistema penal e na sociedade. Tese (Doutorado em Direito) - Faculdade de Direito, Universidade de São Paulo. 2006.

ROSA, P. O. Drogas e a governamentabilidade neoliberal: uma genealogia da Redução de Danos. Florianópolis: Editora Insular, 2014.

SANTOS, J.A.T; OLIVEIRA, M. L. F. Políticas públicas sobre álcool e outras drogas: breve resgate histórico. Saúde e Transformação Social, ISSN 2178-7085, Florianópolis, v.4, n.1, p.82-89, 2013.

STRANG, J. (1990). The roles of prescribing. In J. Strang \& G. Stimson (eds.) AIDS and drug misuse (p.142-152). London: Routledge. 